\title{
Syria mission: safe is a relative term for Ottawa doctor
}

$\mathrm{D}$ r. Susie Tector left Ottawa, Ontario this winter with the best of intentions: to open a new hospital in the opposition-held northern province of Idlib in the Syrian Arab Republic.

The region had two impromptu field hospitals, one in a former chicken factory, and the other in the basement of a mosque, where health workers were providing first aid and some surgeries. But it desperately needed a hospital.

Before the two-year-old civil war, Syria had a fully functional medical system including well-trained physicians and nurses. Now there are 70000 people dead and a decimated health care system.

Tector, an emergency department doctor at the Montfort Hospital, had been on seven other missions in as many years with Médecins sans Frontières (MSF) Canada, including to Chad, Darfur in western Sudan, the Democratic Republic of the Congo and Pakistan. Much of this previous work was as a clinician, but she'd also found a stint as a coordinator challenging.

In Syria, her assignment was to turn a house in a small village into a maternal and child hospital with delivery rooms, an operating room and 22 beds. The village, which cannot be named for security reasons, was close to the fighting, but was reportedly safe.

But when Tector arrived in midFebruary with a logistician and field coordinator, she witnessed shelling in the village and surrounding area.

"I wondered if this [shelling] was new, but the villagers said 'No'," Tector says. "Safe to them meant relatively safe. It meant being shelled once or twice a week. Unsafe meant airstrikes or more frequent shelling."

"Living in a village that was shelled every few days just became normal for them," she says. "The new normal."

It also became normal for Tector. The first night, she barely slept. "I could hear the sounds of shelling in nearby villages, but by the second night, I only awoke if the shelling was

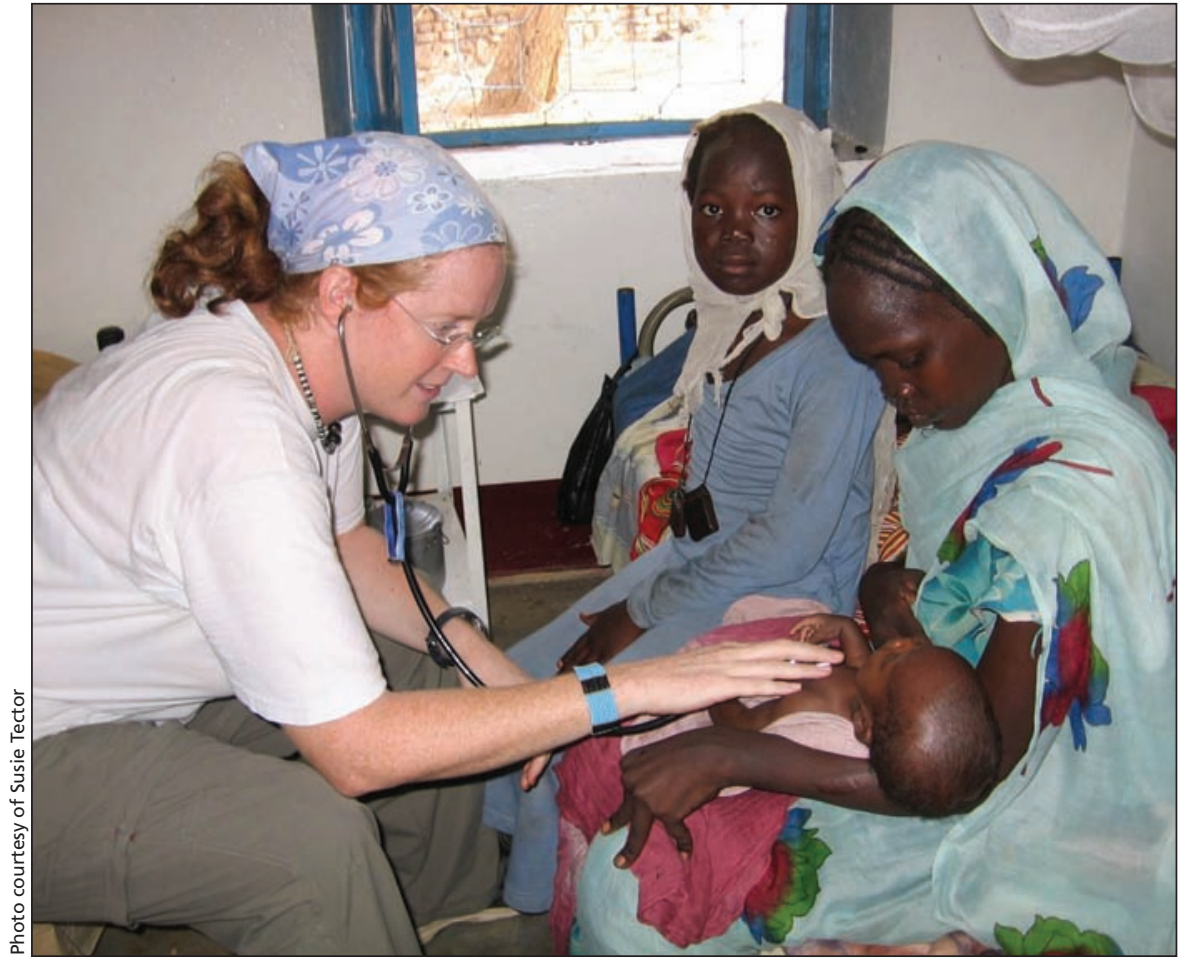

Prior to her recent work in Syria, Dr. Susie Tector had been on seven missions with Médecins sans Frontières (MSF) Canada, including to Chad, the Democratic Republic of the Congo and Pakistan. Here she tends to patients in Darfur.

particularly close to our village, and I slept relatively well," she recounts. "It surprised me how quickly you grow accustomed to it."

"For the people living in these villages, it had been a part of their daily lives for many months, so they have learned how to cope as best they can. I often took my cues from the local people I met, including from our neighbour across the street. She was often out on her balcony putting out laundry and performing other chores. When I would hear a shell landing nearby, I would watch what she did. Did she glance up, and then go back to her work? Or did she yell for her children playing on the roof to come into their house? Or most worrying, did she gather them all and hustle them down to the street, behind the sandbags that line the ground floor of the building? When she let them go back to running and playing in the street or roof, I felt like I could relax.
Tector and her team stayed in the village less than a week, checking out the existing medical facilities.

"Ping pong tables were being used as examining tables," she says. "They are doing the best they can with what they have: one doctor and one assistant." Dentists, medical students and nurses were working as doctors, she added. "They re-use supplies that are disposable. They're clean, but they can't sterilize things. There's no way of doing it."

Any medical facilities that still functioned were geared to trauma, leaving patients with chronic conditons such as diabetes, with nowhere to go. "Diabetic [patients] with no access to insulin end up with complications, with amputations, and dying," she says.

MSF donated dialysis equipment to one of the hospitals and set up a blood bank to replace a previous one that was bombed. 
To be protected from shelling, many children slept in damp, musty caves near the village. Many contracted respiratory infections, skin diseases or had asthma flare-ups. Tector and her team made the difficult decision that they would not be able to set up a hospital.

"It was heartbreaking," she says. "Finally, they see someone from the outside coming in to help. But for us, it was unsafe."

After leaving the village, Tector travelled north to work at one of four MSF hospitals in Syria. The 20-bed hospital, set up in a house, treated burn victims. Because temperatures were in the 5-degree Celsius range in March, people in nearby camps for internally displaced people were burning whatever they could in makeshift stoves sometimes with tragic consequences. In response, the hospital established a well-functioning burn unit, including physiotherapy and skin grafting.

"One patient was a six-week old who was in her mother's arms when the stove exploded," Tector says.

A psychiatrist also worked with burn and trauma victims. "What they've seen breaks your heart," says Tector. "The secondary medical aspects [of the war] became as much or more of a problem as the injuries or trauma. Trauma isn't easy, but it's more straightforward than other problems." Tector returned to Canada on March 28 - a week earlier than planned. She feels "definitely frustrated" that she couldn't help open the hospital.

"Still, I was able to do things not in the original plan," she says. "It puts life here into perspective." - Barbara Sibbald, CMAJ

CMAJ 2013. DOI:10.1503/cmaj.109-4504

Editor's note: This is the third of a three-part series on Syria available at cmaj.ca: "Physicians, health facilities targeted in war-torn Syria" and "Needs escalate, capacity stagnates in Syria." 